\title{
Türkiye'de Kentsel Tasarım Yarışma Pratiği: Tanımlar, Ölçekler, Aktörler
}

\author{
Zeynep Eraydin ${ }^{1}$ \\ ORCID: 0000-0002-5505-7990
}

\author{
Pelin Yoncac1 Arslan ${ }^{2}$ \\ ORCID: 0000-0003-3908-0653
}

\section{Öz}

Cumhuriyetin ilk yıllarından bu yana yarışmalar birçok kentin mekânsal gelişiminde önemli rol oynamıştır. 1927 yılında Ankara'nın planlanması ile başlayan yolculuk 1930'da Bursa Belediyesi Hal Binası ile bir süre tek yapı ölçeğinde devam etmiştir. 1932'de tekrar Ankara, 1942'de Samsun, 1944'te Ödemiş Imar Planları yarışmalar ile kapsam ve ölçek büyümüş, 1945'te Malatya ve Mersin Spor Alanları yarışmaları ile yapı ya da yapılar bütünü özelinde kurulan tasarım problemi çevre ve açık alan tasarımını da içermeye başlamıştır. 1948'de Ulus Meydanı yarışması ile devam eden bu seriyi kampüs tasarımları ve az sayıda da olsa açılan çevre düzenleme yarışmaları izlemiştir. "Mevzii İmar planı", "Turistik Yerleşme Planı", "Kent Bütünü İmar Planı" gibi yarışma alanına özgü adlandırmalardan oluşan yarışmalar dili, 1981 yılında "Eskişehir Fuarı ve Dinlence Ĕ̆lence Kültür Alanları Kentsel Tasarımı" yarışması ile ilk kez kentsel tasarım alanını işaret etmiştir. Bu yarışmayı takiben, 1980'den günümüze kadar uzanan dönemde ise Türkiye'de ulusal ve uluslararası toplam 111 adet kentsel tasarım yarışması düzenlenmiştir. 1980-2020 arasındaki yarışmaları inceleyen bu çalışma, tanımlar, alanlar, katılımcılar, ölçek ve yarışma süreçlerini kapsayan konularda istatistiki analizler üretmiş ve yarışma tarihinden bakarak günümüz tasarım ortamına dair çok sesli ve katılımoı tasarım yöntemleri, disipliner çeşitlilik ile kent kültürüne katkı konularında çıkarımlarda bulunmuştur.

Anahtar Kelimeler: kentsel tasarım yarışmaları, Türkiye, disiplinler arası

\footnotetext{
${ }^{1}$ Dr. Öğr. Üyesi, TED Üniversitesi, E-mail: zeynep.eraydin@tedu.edu.tr

${ }^{2}$ Dr. Öğr. Üyesi, ODTÜ, E-mail: pyoncaci@metu.edu.tr

idealkent (c) Kent Araştırmaları Dergisi (Journal of Urban Studies) 


\title{
Urban Design Competitions in Turkey: Definitions, Scales and Actors
}

\author{
Zeynep Eraydin ${ }^{3}$ \\ ORCID: 0000-0002-5505-7990
}

\author{
Pelin Yoncaci Arslan 4 \\ ORCID: 0000-0003-3908-0653
}

\begin{abstract}
Since the Early Republic, competitions have played an important role in the spatial development of Turkish cities. It started with the planning of Ankara in 1927 and continued for a while in 1930 with the Bursa Municipality State Building Competition. The scope and scale of the projects have grown considerably with new competitions for Ankara in 1932, Samsun in 1942, and Ödemiş in 1944. This series was followed by campus designs and landscape design competitions, albeit in small numbers. The language of competitions was formed by using names specific to the competition site and program, such as "Local Development Plan", "Tourist Settlement Plan", "Urban Renovation Plan." The first time in 1981, "Eskişehir Fair and Recreational, Cultural Entertainment Areas Urban Design Competition" carried the term urban design to the title of a competition. This study examines 111 national and international urban design competitions held in Turkey since 1980s. By producing statistical analyses based on relativly scarce records of these professional events, it problemitizes competitions' definitions, participants, participatory design methods, proposed disciplinary diversity and significant contribution to urban culture regarding today's design environment.
\end{abstract}

Keywords: urban design competition, Turkey, multidisiplinarity

\footnotetext{
${ }^{3}$ Assist. Prof. Dr., TED University, E-mail: zeynep.eraydin@tedu.edu.tr

${ }^{4}$ Assist. Prof. Dr., METU, E-mail: pyoncaci@metu.edu.tr

idealkent @ C Kent Araştırmaları Dergisi (Journal of Urban Studies) 


\section{Giriş}

2020 yılının ilk yarısından itibaren İstanbul Büyükşehir Belediyesi'nin öncülük ettiği ve daha sonra Bursa ve Ankara Büyükşehir Belediyeleri gibi büyük kentlerin de takip ettiği bir dizi kentsel tasarım yarışması açıldı ve halen de açılmaya devam etmektedir. Haliç kıyı bandı, Taksim Meydanı, Kadıköy Meydanı, Bakırköy Meydanı, Bursa Çarşıbaşı Hanlar Bölgesi, Ankara Sıhhiye Kavşağı gibi, kentlere kimliğini veren önemli odak alanları konu alan bu yarışmalar, kapsamları, karar süreçleri, katılımcları ve kazananları ve sonrasında ürettiği eleştirel mesleki diyalog ortamları ile son döneminde en çok konuşulan konu haline gelmektedir. Bu tip yarışmaların, karar vericiler tarafından kentlerin geleceğinin geleneksel yöntemle belirlenmesinden farklı olarak, çok disiplinli bir katılımcı gruplarının bir diğer deyişle yarışmacı ekiplerinin fikirlerini sunmalarına olanak sağlayan bir süreç olduğu aşikârdır. Tek sesli yapıyı çok sesli hale getiren bu sürecin, idareler tarafından özellikle son yıllarda benimsenen ve tercih edilen bir araç haline gelmesi sevindiricidir. Ancak bu yönelim bir süredir üzerinde durulmayan bazı mesleki soruları da beraberinde getirmektedir. 2010 yılında Planlama Dergisinin iki ayrı sayı ayırarak yayınladığı Şehir Planlama Yarışmaları sayıları ve akabinde üretilen Yarışmalar Dizini bu anlamdaki en kapsamlı araştırmalardan biridir. Geçen on yılın ardından kentsel tasarım yarışmalarının hem yapılı çevreyi şekillendirmedeki etkisini, hem de mesleki formasyonun oluşmasındaki rolünü yeniden düşünmek bugünlerde yeniden canlanan yarışma enerjisine ışık tutacaktır.

Antik dönemden bu yana önemli kamu binalarının ve kamusal alanların tasarımcılarını seçmek amacı ile kamu ve özel kuruluşlar tarafından tasarım yarışmaları kullanılmaktadır (Lipstadt, 2003). Aynı şekilde planlama ve kentsel tasarım yarışmaları da kente dokunmanın yeni yollarını üretmek için tarih boyunca en önemli araçlardan biri olmuştur (Gosling ve Maitland, 1984). Yarışmalar tarihine bakıldığında bilinen en erken örnek, MÖ 488 yılında, Atina Akropolünün içine dikilmesi önerilen Zafer anıtı için açlan yarışmadır (De Haan 1988). Ortaçağ döneminde her ne kadar sayıları azalsa da yarışma kültürü varlığını sürdürmüş, on beşinci yüzyıla gelindiğinde Floransa Vaftizhanesi ve Katedrali için açılan yarışmalarda Lorenzo Ghiberti ve Filippo Brunelleschi arasındaki rekabet detaylarıyla yazılmıştır (De Haan, 1988). 1665'te yine bir yarışma ile elde edilen Louvre ve 1717 deki yarışma ile sonuçlandırılan Roma'daki İspanyol merdivenleri de tasarım alanındaki rekabetin en bilinen anıtlarındandır. 
Özellikle mimarlık eğitiminde önemli bir rol oynamaya başlayan yarışmalar akademik ortamda da teori ve pratiğe katkısı ile tartışlır hale gelmiştir (Tostrup, 1999). 20. yüzyılın başlarında Avrupa genelinde kabul edilen temel yarışma ilkeleri (Svensson, 2008) sonrasında tasarım yarışmalarının farklı motivasyonlar ile kent mekanındaki etkileri artmıştır. Şahin'e (2010) göre bu motivasyonlar iki başlık altında değerlendirilebilir; yarışmalar bir yandan serbest piyasa koşullarında özel sektörün kentsel mekanda kendini gösterme aracı olarak ele alınırken, diğer yandan ise özellikle yüzyıl başlarında yeni kurulan ulus devletlerin kendi kimliklerini ortaya koyabilmelerini sağlayan bir araç olarak değerlendirilmektedir. 1950ler ile birlikte kentsel tasarımın planlama teorisi içinde kendine yer bulmaya başlamış ve José Luis Sert başkanlığında 1956'da Harvard Üniversitesinde düzenlenen Kentsel Tasarım Konferansı, kentsel tasarım alanı "mimar, peyzaj mimarı ve şehir planclarının ortak çalışması" olarak tanımlanmıştır (Barnett, 2009; Sert, 1956;). Bu dönemden itibaren bu değişim etkisi yarışmalar pratiğinde de kendini göstermeye başlamıştır. 1980'lerde dünya genelinde yaşanan ekonomik ve politik dönüşümler ve dolayısı ile baskın olmaya başlayan neoliberal politikalar doğrultusunda yarışmaların içeriği ve ele alınışında bir değişim/dönüşüm yaşanmıştır. Bu dönemde özellikle devletin kamusal mekanlar üzerindeki etkinliğinin zayıflaması ve özel sektörün belirgin bir şekilde varlığını hissettirmeye başlaması, yarışmalar ile mekan üretimini destekler hale gelmiştir. İlerleyen dönemlerde dünyada kentlerin, rekabet ile birlikte ortaya çıan markalaşma problemi üzerinde durmaya başlaması, yerel düzeyde de yarışmaların önemini arttırmıştır.

Bütün bunlara rağmen, kentsel tasarım politikaları ve uygulamaları üzerine oluşturulmuş literatür, yapılı çevreyi şekillendirmede tasarım yarışmalarının oynadı̆̆ı rolü öne çıkarma eğiliminde değildir. Nispeten sınırlı sayıdaki yayınların bazıları bu yarışmaları mimari yarışmalarla beraber ele almış (Alexander ve Witzling, 1990; Banerjee ve Loukaitou-Sideris, 1990; Collyer, 2004; De Haan, 1988; Spreiregen 1979), bazıları da politik söylemlerle ilişkilendirip siyasal bir perspektiften değerlendirmiştir (Jessop, 2002; Lipstadt 2006; Sagalyn, 2006). Yarışma ile yapma yöntemi, katılımcllar, projeler, jüri raporları, sonuçların bildirilmesi, halka sunumu/anlatımı ve katılımcı süreçler, mesleğin içinden ve meslekte olmayanlar üzerinde yapılar çalışmalar, yarışmalar yazınının tartıştığı konulardan sadece birkaçı olarak göze çarpmaktadir.

Türkiye'de yarışma süreçleri tarihi incelendiğinde yeterli belgelemenin yapılmadığı, profesyonel anlamda yapılandırılmış bir arşivin bulunmadığ 
görülmektedir. Ancak yine de elde olan yarışma tanımları, şartnameler ve ulaşılabilen proje önerilerine yakından bakıldığında, çok sesli ve katılımcı tasarım yöntemleri, kent kültürüne yapılan katkı, yarışmacı tasarımclar ve yarışma süreçleri hakkında ipuçlarına rastlanmaktadır (Çimen, 2010 ve 2013; Özdağlar ve Yılmaz, 2004). Bu amaçla başlanan bu çalışmada literatür analizi ve dizin çalışması yapılarak 111 adet yarışmadan oluşan bir veri tabanı oluşturulmuştur. Bu veri tabanı önce kategorilere ayrılmış, daha sonra istatistiki yöntemlerle sayısal ve coğrafi veri analizine tabi tutulmuştur. 1980-2020 yılları arasındaki 40 yıllık zaman diliminde yarışmalar üzerinden okunacak tarihsel gelişim ve değişim sürecini konu alan bu çalışma, alanlar, disiplinler arası farklar, süreç ve uygulama problemlerini kapsayan konularda istatistiki analizler sunmakta ve yarışma tarihinden bakarak günümüz tasarım ortamına dair çıkarımlarda bulunmaktadır.

\section{Türkiye'de Kentsel Tasarım Yarışmalarına Hızlı Bir Bakış}

Ülkemiz özelinde baktığımızda Cumhuriyetin ilk yıllarından bu yana yarışmaların birçok kentin mekânsal gelişiminde önemli rol oynadığı görülmektedir. 1927 yılında Ankara'nın planlanması için açılan sınırlı uluslararası şehircilik yarışması kentsel ölçekteki ilk yarışma niteliğini taşımaktadır. Seçim süresi altı ay süren ve sonuçların üç aşamada belirlendiği yarışmada Hermann Jansen'in plan önerisi birinci seçilirken Leon Jaussely ikinci olur (Bilsel, 2010). Uygulamaya geçildiği ilk yıldan itibaren sorunlarla karşılaşılmasına, Jansen ismini plandan sildirmesine rağmen 1955'te açılacak yeni yarışmaya kadar bu plan yürürlükte kalmıştır (Altaban, 1998). Bu yarışmayı 1933 yılında İstanbul İmar Planı için açılan yarışma izlemektedir. Benzer anlaşmazlıklara sahne olan ve yine uluslararası katılımcıları olan bu yarışmayı "rasyonel" önerisi ile Alman şehirci Hermann Ehlgotz kazanır, fakat plan uygulanmaz (Bilsel, 2010). Eş zamanlı olarak 1930'da Bursa Belediyesi Hal Binası Mimari Proje Yarışması ile tek yapı ölçeğinde yarışmalar başlar. 1932'de tekrar Ankara, 1942'de Samsun, 1944'te Ödemiş İmar Planları yarışmaları ile kapsam ve ölçek yeniden büyümüş, 1945'te Malatya ve Mersin Spor Alanları yarışmaları ile yapı ya da yapılar bütünü özelinde kurulan tasarım problemi yerini çevre ve açık alan tasarımına bırakmıştır. 1948'de Ulus Meydanı yarışması ile devam eden bu yaklaşım, yine 1951'de İzmir İmar planı, Eskişehir, Malatya, Ankara, Antalya İmar planları yarışmaları ile devam etmiştir. Bu seriyi kampüs tasarımları ve az sayıda da olsa yine de açılmaya devam eden çevre düzenlemesi yarışmaları izlemiştir. Uluslararası şehircilik yarışmaları ile baş- 
layan planlama yarışmaları süreci 1940'larda İller Bankası, 1960 ve 1970 döneminde ise Bayındırlık Bakanlığı, İmar İskan Bakanlığı'nın yarışmaların kurumsallaşmasında etkin rol almasıyla gelişmiştir. (İdil, 2010; Şahin, 2010).

Bu noktada İller Bankası' nı ayrıca ele almak yararlı olacaktır. Banka, 1965 yılından bu yana 11 adet imar planı yarışmasının şartnamesi, yarışma süreci ve proje değerlendirmesi ile yarışmalar sürecinde önemli bir standart ve açılım oluşturarak katkı sağlamıştır (Gülgeç, 2010). Gülgeç'e göre özellikle yarışmacılara verilecek veri paketinin oluşturulmasında yeni yöntemler uygulanmıştır. Kentin o günkü durumunu anlatabilmek için jeolog, ekonomist, sosyolog, coğrafyacı, matematikçi gibi farklı disiplinlerden uzmanlar tarafından alan araştırmasına ve gözleme dayalı bilgi paketleri oluşturulmuş, toplanan verilerle metin ve çizimler hazırlanmış ve yarışmacılarla paylaşılmıştır. Sonuçlar açiklandıktan sonra değerlendirilen projeler sergilenmiş ve halk ile buluşması sağlanmıştır. Böylece düzenli olarak ulusal ve kimi yarışmalarda uluslararası tasarım ekiplerinin ilgisini çeken yarışmalar, toplumun farklı gruplarının da izleyebileceği ve kamuoyunda merak uyandıran kültürel faaliyetlere de dönüşmeye başlamıştır. Bu süreçlerin devamında İller Bankası “İmar Planına Esas Olacak Ön Çalışma (Analitik Etütler)" başlıkları altında, ön belgelemeleri ve projeleri içeren kitaplar bastırmıştır. Hem uygulamaya hem de fikir üretimine yönelik üretilen sonuç ürünler, kentlerin geleceğine ilişkin gelişim senaryolarının ilk kez ortaya atıldığı, çok disiplinli katılımın görülmeye başladığı mesleki ortamları oluşturmuştur. 8 Ocak 1978 tarihinde Cumhuriyet Gazetesi'nde İller Bankası tarafından yayınlanan, İzmir Kenti Kıyı Düzenlemesi yarışmasının paftalarının Ankara Zafer Çarşısı Güzel Sanatlar Galerisinde sergileneceği haberi, yarışma ile elde edilen ürünlerin kamuoyu tarafından da yakından izlendiğini göstermektedir. Dolayısıyla, 1980lerden itibaren yarışmalara - yalnızca uygulamaya yönelik değil, aynı zamanda kamuoyunun da bilgilendirildiği süreçler olarak bakmakta fayda bulunmaktadır (Lehrer, 2011). Farklı ölçek ve kapsamlarda düzenlenen bu yarışmalarda, kentsel mekâna dair fikirler üretilmiş, kimi zaman gelenekselci kimi zaman yenilikçi kavramlar tartışılmış ve kentlerin geleceğine ilişkin kararlar ortaya konmuştur.

1980 sonrası dönemde kentsel tasarım yarışma sayıları giderek artıp mimarlık ve kentsel tasarım yarışmaları şeklinde yeni bir birliktelik oluşurken, şehir planlama yarışmaları varlığını belirgin bir şekilde kaybetmiştir. "Mevzii İmar planı", "Turistik Yerleşme Planı", "Kent Bütünü İmar Planı" gibi yarışma alanına özgü adlandırmalardan oluşan yarışmalar dili, ilk kez 1981 y1lında “Eskişehir Fuarı ve Dinlence Eğlence Kültür Alanları Kentsel Tasarımı” 
yarışması ile kentsel tasarım alanını telaffuz etmiştir. Bu dönem itibariyle planlama yarışmaları yerini kentsel tasarım yarışmalarına bırakmıştır. Bu süreci tetikleyen ilk önemli etken 1984 yılında imar planı yetkilerinin merkezden belediyelere devredilmesi ve dolayısıyla yerel yönetimlerin mekan üretimi konusunda ön plana çıkmasıdır (Özaydın, 2008). Diğer bir gelişme, 12.03.1988 tarihinde yürürlüğe giren TMMOB Mimarlar Odası Mimarlık Mühendislik Şehircilik ve Kentsel Tasarım Proje Yarışmaları Yönetmeliği'dir. Yarışma türleri, uygulama esasları, jüri üyeleri ve görevleri, yarışma süreci, sonuçlandırılması, tarafların hak ve sorumlulukları gibi konularda detaylı kararlar içeren yönetmelik, yarışmaların şekillenmesi ve meslek grupları tarafindan algılanması konusunda önemli bir yere sahiptir. Belgenin detaylı incelenmesi yapıldığında kentsel tasarım kavram, kapsam ve sürecine yönelik önemli eksiklikler içerdiği öne sürülse de, bu belgenin bağlayıcılı̆̆ında birçok kentsel ölçekte tasarım yarışması düzenlenmiştir (Bayraktar, Kaplan ve Tekel, 2006). Şahin (2010) kentsel tasarım yarışmalarının sayısındaki bu artışta dünya genelindeki neoliberal politikalar ile birlikte yerel yönetimlerin daha etkin hale gelmesinin etkili olduğunu söylemektedir. Benzer şekilde, Sayar (2004) kentsel mekanın üretilmesi sürecinde küreselleşmenin ve buna bağlı olarak ekonomik büyümenin etkisi olduğunu ve bunun da yarışmaların içeriklerini değiştiğini öne sürmektedir. Bu çerçeveden bakıldığında kentsel tasarım yarışmaları, kent mekanı için cesur kabul edilebilecek deneysel fikirlerin öne sürülmesine olanak sağladıkları için tasarım laboratuvarları olarak da tanımlanmaktadır (Larson, 1994; Lipstadt, 2003; Malmberg, 2006). Daha öznel bakıldığında ise, tasarımcılar için yarışmaların medyanın ilgisini çekme ve kamuoyunda yer almayı sağlama gibi işlevleri de göz ardı edilmemelidir (Sudjic, 2006).

Bu ilginin beraberinde getirdiği kapsayıc bir yönetmelik ihtiyacı sonucunda 2002 yılında “Mimarlık, Peyzaj Mimarlığı, Mühendislik, Kentsel Tasarım Projeleri, Şehir ve Bölge Planlama ve Güzel Sanat Eserleri Yarışma Yönetmeliği" ortaya konmuş ve yarışmalarda izlenecek yol tarif edilmiştir. Yönetmelik içinde yarışmaların hedefleri "ait olduğu konu özelinde; kültür, sanat, bilim ve çevre değerlerinin rekabet yoluyla geliştirilmesine, çok sayıda seçenekten en ekonomik, en işlevsel ve yenilikçi çözümlerin seçilmesine, müelliflerinin saptanmasına ve güzel sanatların teşvikine ve yönetmelik kapsamına giren mesleklerin gelişmesine, etik değerlerin yerleşmesine, uluslararası rekabet gücü kazanmalarına uygun ortamı sağlamak" olarak tanımlanmıştır. Kentsel tasarım yarışmaları, mimari ve peyzaj projeleri ile pek çok ortak noktaya sahip olsalar da, büyük kent parçalarından kısıtlı kamusal alanlara kadar 
çeşitli ölçeklerde ele alınabilen ve mimari ve mimari olmayan unsurları da içeren tasarım problemleri tanımladıkları için önemli farklılıklar içermektedirler (Sagalyn, 2006).

\section{Sayılarla Kentsel Tasarım Yarışmaları}

Türkiye'de kentsel tasarım adı ile açılan ilk yarışma İller Bankası Genel Müdürlüğünce 1981 yılında açılan Eskişehir Fuarı ve Dinlence Eğlence Kültür Alanları Kentsel Tasarım Yarışmasıdır. Mimarlar Odası Mimarlık ve Şehircilik Yarışmaları Yönetmeliği temel alınarak açılan yarışma, Eskişehir'in artan nüfusuna karşı yetersiz açık alan sorununa çözüm aramayı amaçlamakta ve alanın iyileştirilmesi, düzenlenmesi ve kentlilere kazandırılmasını öngörmektedir. Bu yarışmayı takiben 1980-1989 döneminde kentsel ölçekte 14 yarışma açılmış ancak bunların 6 tanesi çevre düzenleme kapsamında ele alınırken, yalnızca 8 tanesi kentsel tasarım yarışması olarak nitelendirilmiştir. Bu yarışmalar içinde park ve rekreasyon alanlarının yanı sıra meydan düzenlemeleri (İstanbul Beyazıt Meydanı, İstanbul Üsküdar Meydanı, İstanbul Taksim Meydanı, Bursa Zafer ve Şehreküstü Meydanları) ön plana çıkmaktadır.

1990-1999 döneminde kentsel ölçekte açılan 20 yarışmanın 8 tanesi kentsel tasarım yarışması iken 14 tanesi çevre düzenleme ve peyzaj mimarlığı yarışması adı ile düzenlenmiştir. Açlan kentsel tasarım yarışmalarında yine farklı ölçekler ve içeriklerde kent parçaları ele alınmış ve bir kısmı fikir bir kısmı ise proje yarışması olarak düzenlenmiştir. Bir önceki dönemden farklı olarak bu dönemde açılan yarışmaların bir kısmında daha planlama ölçeğine yakın büyük kentsel alanları konu alan yarışmalar (Ankara Merkezi İş Alanı Planlama ve Geliştirme Yarışması, Gaziantep Merkezi Hal Bölgesi Koruma Geliştirme Amaçlı Kentsel Tasarım Yarışması, Bandırma Belediyesi Cin Çukuru Kent Merkezi Düzenleme Yarışması) olarak düzenlenmiştir. 


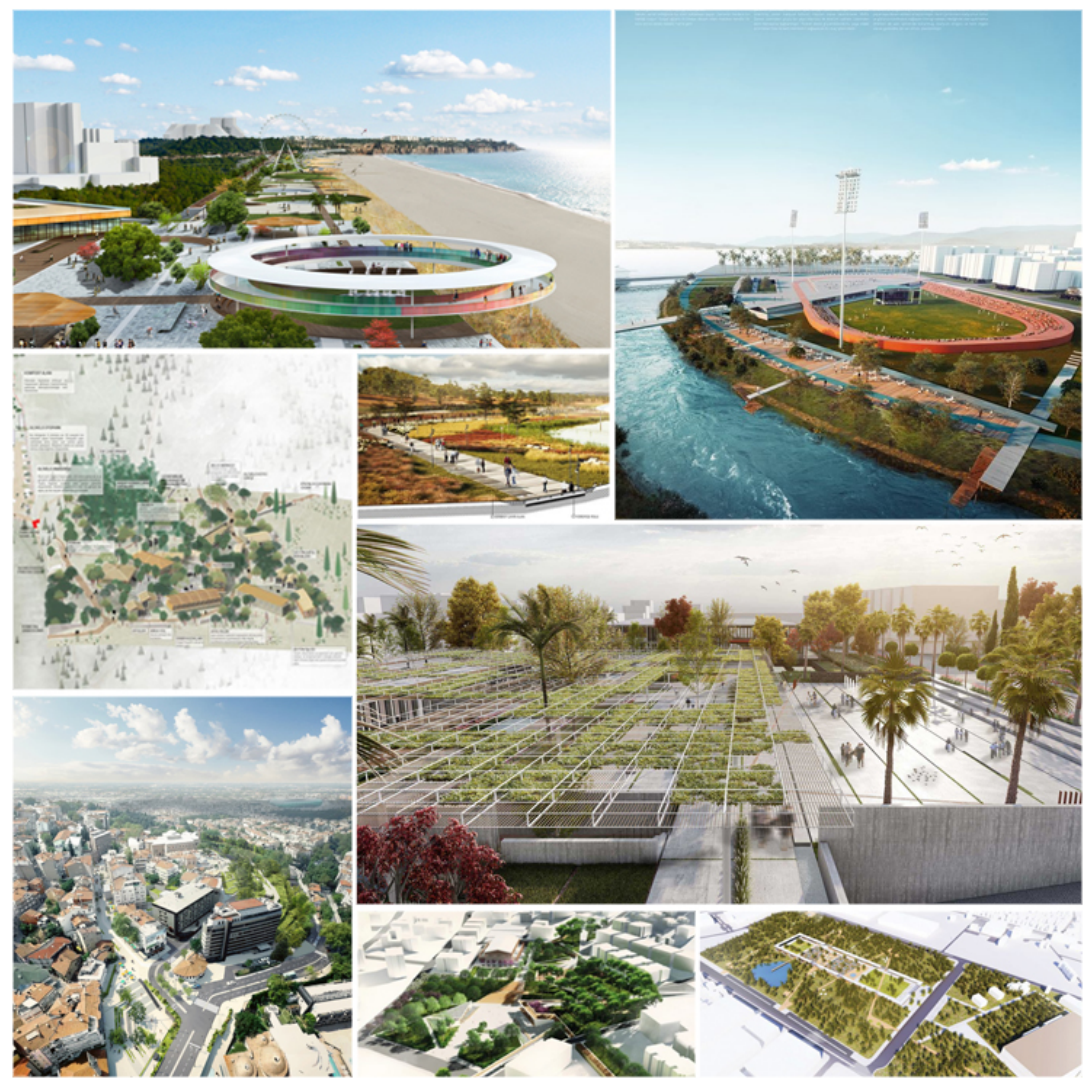

Şekil 1. Ödül almış kentsel tasarım projelerinden oluşturulmuş bir kolaj

(Arkitera, t.y)

2000'li yıllar ile birlikte kentsel tasarım yarışmalarının sayısı giderek artmaya başlamıs, 2000-2009 yılları arasında toplam 37 adet kentsel ölçekte yarışma düzenlenmiştir. Bunların arasında sadece 9 tanesi çevre düzenleme kapsamında ele alınmış, 28 adet yarışma ise yalnızca kentsel tasarım ya da kentsel tasarım ve mimari proje yarışması şeklinde açılmıştır. Bu dönemde açılan kentsel ölçekli yarışmaların kapsamının daha önceki yıllara göre daha geniş olduğunu söylemek yanlış olmayacaktır (Şekil 1). Bir kent parçasından (Küçükçekmece Kent Merkezi, Gebze Tarihi Kent Merkezi), park ve rekreasyon alanına ve kentsel açık alanlara kadar birçok farklı ölçek ve kapsamda yarışma çeşitliliği gözlemlenmektedir. Maltepe Bölge Parkı Fikir Proje Yarışması, Urla Çeşme Karaburun Yarımadası Ulusal Fikir Yarışması, Konyaaltı Doğa ve Kültür Parkı Alanı Mimari ve Çevre Düzenleme Proje Yarışması gibi projelerde hem peyzaj hem de şehircilik anlamında önemli fikirler üretilmiştir. 
2010 yılından günümüze kadar olan dönemde ise yarışma yolu ile proje elde etme yönteminin idareler tarafından daha çok benimsendiği görülmektedir. Toplam 40 adet kentsel ölçekte yarışma düzenlenmiş ve bunların 24 tanesinde kentsel tasarım ifadesine yer verilmiştir (Tablo 1). Yine bir önceki dönemde olduğu gibi düzenlenen yarışmalarda farklı ölçek ve kapsamlara yer verilmiştir; Orhangazi Meydanı ve Çevresi Kentsel Tasarım Proje Yarışması, Çanakkale Belediyesi Kent Meydanı ve Çevresi "Yeşil" Kentsel Tasarım Yarışması ve Adana-Seyhan Sucuzade Mahallesi Kentsel Dönüşüm Alanında Kent Meydanı ve Çevresi Kentsel Tasarım ve Mimari Proje Yarışması, gibi.

Tablo 1. Kentsel ölçekli yarışmalar ile kentsel tasarım yarışmaları karşılaştırılması

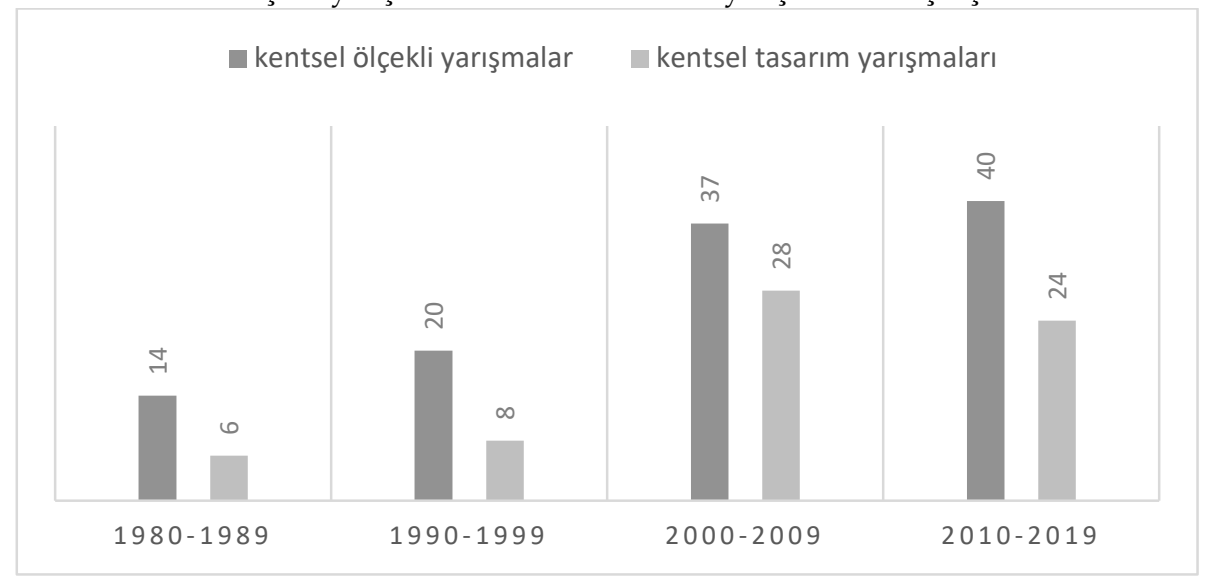

Kentsel ölçekte açlan tüm yarışmalara bakıldığında toplamdaki 81 ilin yalnızca 35 tanesinde bugüne kadar kentsel ölçekte bir yarışma düzenlendiği görülmektedir (Tablo 2). 1980-2020 yılları arasında açılan toplam 111 yarışmanın kentlere göre dağılımına bakıldığında yoğunlukla üç büyük şehir (İstanbul, Ankara, İzmir) ile birlikte Antalya ve Bursa büyükşehirlerinde bir yoğunluk görülmektedir. Son dönemlerde ise belediyelerin yarışmalara olan ilgileri artmaya başladıkça, büyükşehirler dışındaki illerde de yarışma yolu ile proje elde etme tercih edilen bir yöntem haline gelmiştir. 2010-2019 yılları arasında İstanbul'da 3, Ankara'da yalnızca 1, İzmir'de ise 5 adet kentsel ölçekte ulusal yarışma düzenlenmiştir. Diğer yandan ise bu dönemde 16 ilde (Afyonkarahisar, Aksaray, Aydın, Çanakkale, Düzce, Edirne, Elazı̆̆, Kırklareli, Manisa, Mersin, Muğla, Samsun, Sivas, Tekirdağ, Uşak, Zonguldak) ilk defa kentsel ölçekte bir yarışma düzenlenmiştir. 
Tablo 2. Yarışmaların şehirlere göre dağılımı

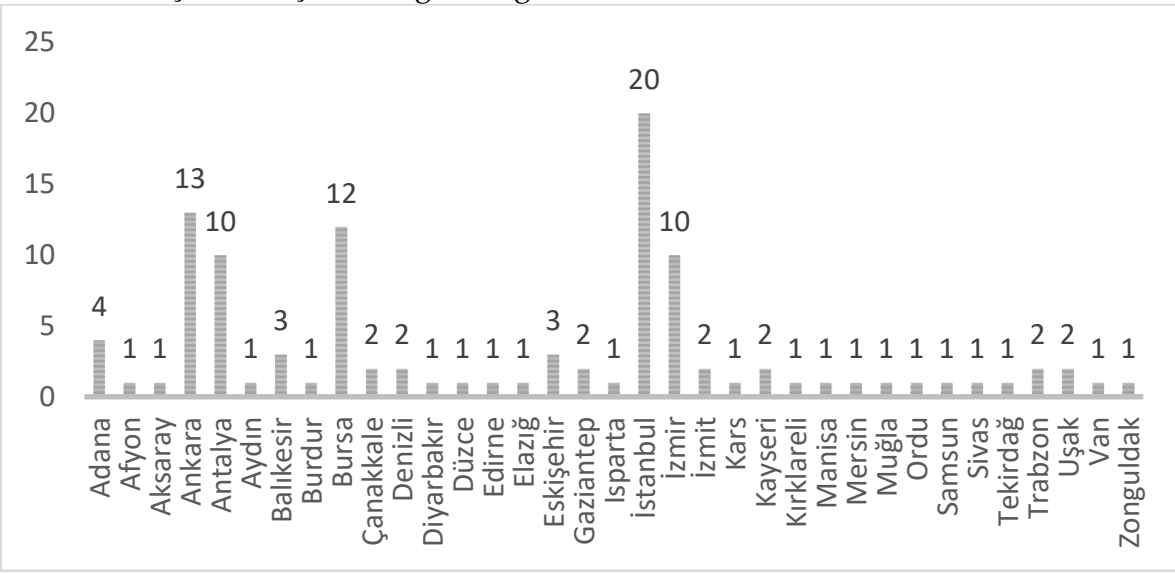

Bu grafiğe harita olarak baktığımızda ise, yarışma ile üretilen projelerin batı illerde yoğunlaştığı görülmektedir. (Şekil 2). Üretilen projelerin kamusal mekana odaklandığı, sosyal ve kültürel aktivitelerin zenginleştirilmesi, kullanım alanlarının çeşitlenmesi, kent mekanının görsel ve estetik değerlerinin artırılması gibi ana hedeflerle tasarlandığından yola çıkıldığında, bu resmin, doğu illerindeki yerel yönetimlerin vizyonları ile ilgili de düşündürücü bir tablo olduğu söylenebilir. Yarışma ile proje elde etme yönteminin bu illerde tercih edilmiyor olmasının çeşitli nedenleri olabilir. Elbette böyle bir konu daha derin başka bir araştırmanın da konusudur. Ancak yarışma ilanın seçilen projenin uygulanmasına kadar olan süreç birlikte değerlendirildiğinde, sürecin tasarlanması ve uygulamaya geçilmesi, şartname hazırlanması, sürecin sekretaryasının tutulması gibi çok aktörlü bir çalışma sürecindeki uzmanlık eksikleri ve beraberindeki maddi yetersizlikler buna neden olan etmenlerden biri olarak düşünülebilir. 1985 yılında yapılan Trabzon Sahil Şeridi Çevre Düzenleme Yarışması'nı istisna olarak alırsak, işaretli illerdeki yarışmalar 2005 ve sonrasına tarihlenmektedir (2005 tarihli Van Beşyol Meydanı Hastane Caddesi Milli Egemenlik Caddesi ve Çevresi Kentsel Tasarım Proje Yarışması, 2006 yılı Dicle Vadisi Peyzaj Planlama, Kentsel Tasarım ve Mimari Proje Yarışması, 2008 tarihli Sarıkamış Harekatı Anma Alanları Fikir Yarışması ve en son olarak 2017 Elazığ Belediyesi Kent Meydanı Kentsel Tasarım Yarışması). Bu şehirlerdeki kentsel mekanlarının halihazırda sürekli değişim ve dönüşüme uğradığını da göz önüne aldığımız da, görece yeni başlayan yarışma pratiğinin bu illerde henüz yerleşmediği görülmektedir. 


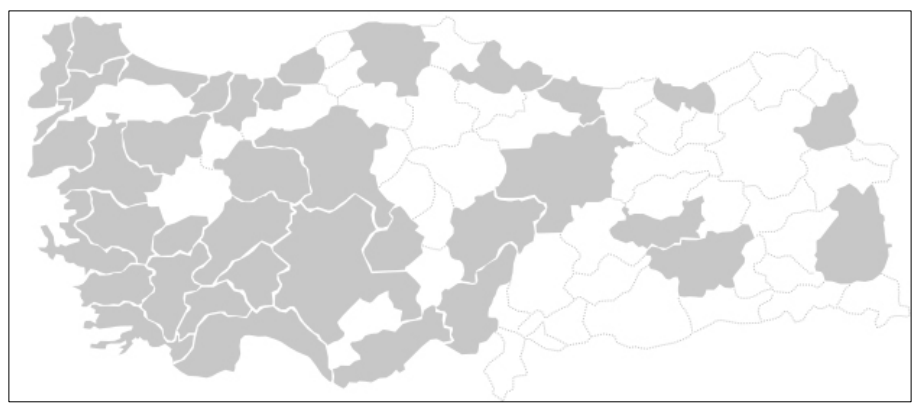

Şekil 2. Yarışmaların şehirlere göre dağılımı

\section{Kentsel Tasarım Yarışmalarn ve Üretilen Bilgi}

Kentsel Tasarım Yarışmalarının Türkiye'de ilk gündeme geldiği 1980 yılından bu yana giderek artan bir şekilde planlama pratiğinin içinde yer aldığ 1 görülmektedir. Yarışmalara daha yakından bakıldığında ise, 1980 öncesi dönemde daha çok planlama yarışmaları olarak hazırlanırken, bu dönemden sonra kentsel ölçek tanımıyla açıldığı ve yarışmaya konu olan alanların birbirinden farklılaştığı görülür. İsimlendirme konusunda bir standart belirlenemeyeceği için, projelerin kategorize edilmesi kolay değildir. Bu nedenle çalışma sırasında yarışma isimlerinden yola çıkarak bir gruplama yapılmıştır. Kent parçası (kent merkezi, kent girişi gibi isimlendirmeleri kapsayan bir tanım), kıyı şeridi, meydan, sokak, rekreasyon alanı ve yapı çevresi olmak üzere altı gruba ayrılmış, 111 proje yakından incelenmiştir. Proje konusu ve ölçek olarak farklılaşan projelere ilişkin yapılan bu sayısal araştırmada, yaklaşı \%35 oranıyla kent parçası ve rekreatif alan konusunun öne çıktığı görülür. Ankara Ulus Tarihi Kent Merkezi Çevre Düzenlemesi Yarışması, Antalya Kent Merkezi içinde Kalekapısı ve Çevresi Kentsel Tasarım Yarışması, Güzel Ankara Projesi Kent Girişleri Düzenlemesi İstanbul Girişi Yarışması, Gaziantep Merkezi Hal Bölgesi Koruma Geliştirme Amaçlı Kentsel Tasarım Yarışması gibi yarışmalar bahsi geçen kent parçasında çok amaçlı kullanım ve kent kimliği odaklı çalışmalar sunmaktadır

Diğer yandan Damlataş Mağarası Çevresi ve 100.yıl Atatürk Parkı Peyzaj ve Tasarım Proje Yarışması, Pananos Plajı (Selçuk) Kentsel Tasarım ve Peyzaj Proje Yarışması, Bursa Kızyakup Kent Parkı Kentsel Tasarım ve Mimari Proje Yarışması, Üçüncü Bin yılda Yaşayan Osmanlı Köyü Cumalıkızık Fikir Proje Yarışması, Eşkinoz Vadisi Rekreasyon Alanı Proje Yarışması ve en son geçen yıl açlan Olivelo-İzmir Kent Çeperinde Ekolojik Ortak Yaşam Alanı Fikir Projesi Yarışması ise rekreasyon odaklı açılan yarışma projelerindendir. Bu 
iki ana yaklaşımı sırası ile meydanlar (\%25), yapı çevrelerine ilişkin düzenlemeler (\%10), kıyı düzenlemeleri (\%4) ve cadde/sokak düzenlemeleri (\%3) takip etmektedir (Tablo 3).

Tablo 3. Yarışma kategorileri ve yüzdeleri (\%)

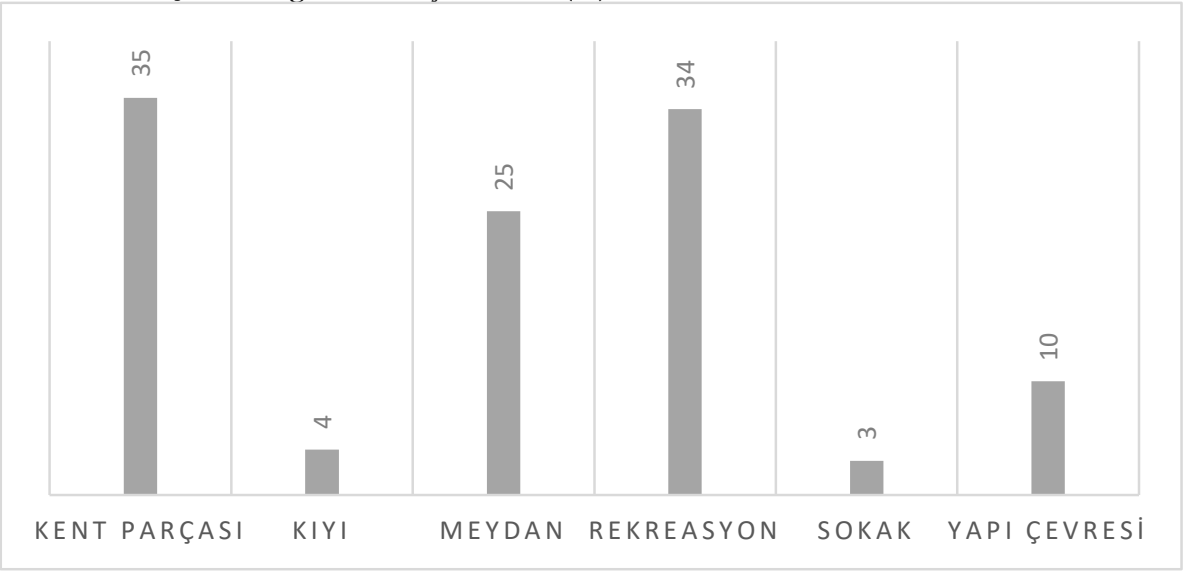

Yarışmaların en büyük kısmını oluşturan kent parçası, rekreasyon ve meydan grubuna tarihsel perspektifte baktığımızda 1980-89 döneminde yarışmaların \%7' sinin kent parçaları ile ilgilenirken, bu rakamın 1990-99 döneminde \%40 a kadar çıktığı görülmektedir (Tablo 4). Buna karşılık, ilk dönemlerde çok sık yer alan rekreasyon alanlarının zaman içinde oranının giderek düştüğü gözlemlenmektedir. Kentsel tasarım pratiğinin en önemli konularından biri olan meydan ve sokaklar gibi kentsel açık alanlar ise ancak 2010lar ve sonrasında ilgi çekici hale gelmeye başlamıştır. Bu okuma, yarışmaya konu alanın ölçeği hakkında fikir vermesinin yanı sıra, kentin parça bütün ilişkisinin ve daha da önemlisi bu ilişkinin idare tarafından nasıl tanımland1ğına da işaret etmektedir. Yarışma şartnamesinde tanımlanan tasarım problemi ve tasarım alanı, katılımcıların hareket alanını tanımlamakta ve fakat bu alanın şehrin bütünü ile olan ilişkisi de her zaman tartışmalara dahil olmaktadır. 1989'da açlan Tarlabaşı Caddesi Düzenlemesi Yarışması, Tarlabaşı'nın kendine özgü kimliğinin pekiştirilmesinde büyük rol oynamıştır. Bu durumda, yarışmada kullanılan isimlendirmenin ölçek vermekten öte, algıyı da şekillendirici bir format olduğunu söylemek yanlış olmayacaktır. 
Tablo 4. Üç ana kategorinin yıllara göre yüzdeleri (\%)

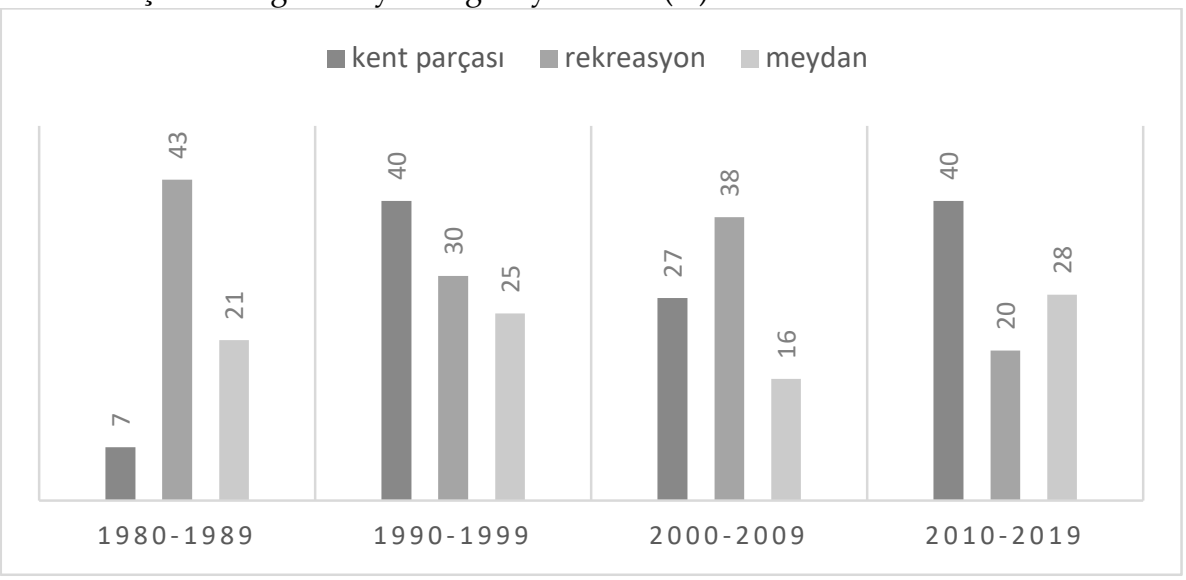

\section{Kentsel Tasarım Yarışmaları ve Katılımo Profilleri}

Yarışmalar konusundaki bir başka önemli konu elbette ki katılımcılardır. Kentsel tasarım yarışmaları birçok farklı meslek insanını buluşturan bir ortam sağlamaktadır. İlk etapta, kentsel mekana dair konuların tartışıldığı, fikirlerin üretildiği bu tip yarışmalarda şehir planlama disiplininin etkin bir şekilde rol aldığı düşünülmektedir. Ülkemizde Kentsel Tasarım programlarının çoğunlukla Şehir ve Bölge Planlama Bölümlerinin altında olduğu düşünülürse bu çıkarımı yapmak yanlış olmayacaktır. Ancak hazırlanan yarışma şartnamelerinde yarışmaya katılım koşullarına bakıldığında durumun bu söylemi destekler nitelikte olmadığı görülmektedir. 1980 yılında günümüze kadar düzenlenen 111 yarışmadan yalnızca 42'sinde (\%38) şehir plancılarının katılımı zorunlu tutulmuştur. Düzenlenen yarışmaların \%62'sinde ise şehir plancılarının yarışmaya katılımı bir ön koşul olarak belirlenmemiştir. Elbette yarışmaların farklı fikirlere açı bir tutum sergilemesi ve fikir zenginliğin ana hedef olması düşünüldüğünde bu tür ön koşulların yarışma ruhuna aykırı olduğu düşünülebilir. Ancak konuya disiplinin kentsel mekanın okunması ve değerlendirilmesi, planlama biliminin ve eğitiminin getirdiklerinin kullanılması penceresinden bakıldığında bu ön koşulun kente dair üst ve alt ölçek ilişkilerinin daha iyi kurulabilmesi anlamında gerekli olduğu da öne sürülebilir. Çok disiplinli yaklaşımın desteklenmesi ve belli disiplinler zorunlu tutuluyorsa, bu gruba kentsel tasarım uzmanlarının da eklenmesinin çıacak tasarım ürünlerinin yarışma alanı ve çevresiyle olan ilişkisini artıracağı aşikardır. 
Kentsel ölçekli bu yarışmalardaki katılım koşulları ile yarışmanın konusu birlikte değerlendirildiğinde ise daha ilginç sonuçlar ortaya çıkmaktadır (Tablo 5a ve b). Elde edilen verilere göre kent parçasını konu alan yarışmaların 19 tanesinde (\%54) şehir plancılarının yarışma ekibi içinde olması zorunlu tutulurken 16 tanesinde (\%46) bu zorunluluk bir ön koşul olarak konmamıştır. Özellikle büyük bir kent parçasını (mahalle, kent merkezi gibi) konu alan yarışmalarda, yarışmaya konu olan alanın kent ile ilişkinin kurulmasının önemi göz önünde bulundurulduğunda planlama disiplininin durduğu nokta ilgi çekicidir.

Tablo 5a. Şehir plancılarının yarışma ekibi içinde olması zorunlu tutulan yarışmalar:

\begin{tabular}{lll}
\hline Yarışma kategorisi & adet & \% \\
\hline kent parçası & $\underline{19}$ & $\underline{45}$ \\
\hline meydan & 10 & 24 \\
\hline rekreasyon & 6 & 14 \\
\hline yapı çevresi & 4 & 10 \\
\hline sokak & 2 & 5 \\
\hline kıyı & 1 & 2 \\
\hline Toplam & $\mathbf{4 2}$ & $\mathbf{1 0 0}$ \\
\hline
\end{tabular}

Tablo 5b. Şehir plancılarının yarışma ekibi içinde olması zorunlu tutulmayan yarışmalar

\begin{tabular}{lll}
\hline Yarısma kategorisi & adet & $\mathbf{\%}$ \\
\hline rekreasyon & 28 & 41 \\
\hline kent parçası & $\underline{16}$ & $\underline{23}$ \\
\hline meydan & 15 & 22 \\
\hline yapı çevresi & 6 & 9 \\
\hline kıy1 & 3 & 4 \\
\hline sokak & 1 & 1 \\
\hline Toplam & $\mathbf{6 9}$ & $\mathbf{1 0 0}$ \\
\hline
\end{tabular}

\section{Kentsel Tasarım Yaruşmaları ve Uygulama Süreçleri}

Yarışmalar Uluslararası Mimarlar Birliğine (UIA) göre fikir ve proje yarışması olarak ikiye ayrılmaktadır. Türkiye'de 1980 yılından bu yana açlan 111 kentsel tasarım yarışmasının 32 tanesi (\%29) "Fikir Yarışması", 79 tanesi (\%71) "Proje Yarışması" olarak açılmıştır. Fikir yarışmaları tespit edilen sorunlara yönelik olarak geliştirilebilecek çözümleri kavramsal ve söylemsel düzlemde ararken, proje yarışmaları daha gerçekçi ve uygulanabilir çözümlere odaklanmaktadır. Dolayısı ile fikir yarışmalarının sonucunda elde edilen projeler daha sonra değerlendirilmek üzere yarışmayı açan idarede kalırken, proje yarışmalarında yarışmada ödül alanların (sıralamaya göre) o projeyi hayata geçirme şansı bulunmaktadır. Ancak bazı durumlarda fikir projeleri de idareye bağlı olarak uygulama sürecine taşınabilir. Her iki türde de gerek 
ödül alan gerek almayan birçok proje elde edilmekte ve bu projeler ile kente dair birçok konu farklı bakış açıları ile değerlendirilmektedir. Bazı fikir yarışmaları sonuçları daha sonra proje üretim sürecine dönüşmüş ve uygulama imkanına ulaşmıştır. Ancak yine de yapılan araştırma gösteriyor ki 1980 yılından bu yana açlan 111 kentsel tasarım yarışmasının yalnızca \%25'i uygulanabilmiştir. Bununla birlikte uygulanma imkanı bulan projelerin bir kısmı kısmen uygulanmış bir kısmı ise değişime uğrayarak uygulanabilmiştir.

Yarışma yolu ile elde edilen projelerin hayata geçmesi uzun zamandır yarışmacılar tarafından tartışılan bir konudur. Yarışmalara ilişkin düzenlenen birçok panel ve kolokyumda idarelerin uygulama safhasında proje sürecini yavaşlattığ1 ya da durduğu tartışılmıştır. Yarışmalar ve Mimarlık Sempozyumu 2016 kitapçığında Ayataç ve Ketboğa (2016) 50 yarışmacı ile yaptıkları ankette yarışmaların uygulanmasının disiplinlere büyük katkısı olduğunu bu nedenle çok önemli bir konu olduğunu belirtmişler ve yarışmaların uygulanma yüzdelerinin çok düşük olmasının bu anlamda bir sorun olduğunu vurgulamışlardır. Aynı sempozyumda yarışmaların uygulama sorunlarına dikkat çeken Sirel ve Sirel (2016) yarışmaların uygulanmamasına ilişkin sorunları yarışmayı düzenleyen kurumdan kaynaklı, jüri oluşumundan, şartnameden ve katılımcılardan kaynaklı sorunlar olarak dört başlık altında ele almışlardır. Bu dört ana başlık tüm yarışmaların uygulama süreçlerinde geçerli iken, kentsel tasarım yarışmalarında yarışmaya konu olan alanların çok daha fazla bileşenli olmalarından dolayı sürecin daha da zor işlediğini de belirtmişlerdir. Bu çalışma için incelenen projelerden de yalnızca dörtte birinin uygulanabilmiş olması bu görüşü destekler niteliktedir.

\section{Tartışma ve Sonuç}

Tarihsel olarak bakıldığında kentsel mekana şekil veren yarışmaların sayısının gün geçtikçe arttı̆̆ görülmektedir. Bu artışın en önemli nedenlerinden biri yarışmaların kentsel mekanın gelişiminde etkin rol oynayan yaratıcı bir mekan üretme yöntemi ve kent mekanına dair farklı sorunlara en iyi çözümün bulunmaya çalışıldığı bir süreç olarak değerlendirilmesidir (Alexander ve Witzling, 1987; Chupin ve Cucuzzella, 2011; Lipstadt, 2006; Rönn, Kazemian ve Andersson, 2010). Bununla beraber hem katılımclara fikirlerini özgür bir şekilde ifade etme olanağı sunma şansı vermesi hem de yarışmayı açan idareye birçok fikri elde etme olanağı sağlaması açısından da giderek benimsenen bir yöntem olmuştur. Amerikan Mimarlar Enstitüsü'ne (2010) göre kentlerin ve kentsel mekanların geleceğinin tartışıldığı yarışmalar aynı zamanda kentlilerin süreçten haberdar olmalarına ve sürece katılımlarına 
olanak sağlaması açısından da planlama ve tasarım kültüründe önemli bir yere sahiptir. Bu anlamda kamu aktörlerinin elinde olan planlama ve katılım ilişkisini güçlendiren bir araç olarak düşünülmektedir.

Bu bağlamda 1980lerden itibaren ülkemizde düzenlenmiş yarışmalar üzerinden yapılan analiz çalışması, sayının artışını, üretilen projelerin kapsam ve konularını ve yere göre dağılımını göstermiştir. Yapılan çalışma sayesinde açlan yarışmaların mekansal girdileri, programları, ölçekleri, kent mekanına dair gelecek projeksiyonları bakımından birbirinden ne kadar farklı olduğunu ortaya koymuştur. Bu heterojen dağılıma rağmen altı başlık altında toplayabildiğimiz projelerin yıllar içinde kentsel politikalar, meslek örgütlerinin yönelimleri ve ekonomik gelişmeler gibi sebeplerle gerçekleştirilme oranı düşük seviyede kalmış ve gerçekleştirilenlerin bile değiştirildiği ve dönüştürüldügü bilgisi çeşitli ortamlarda proje müellifleri tarafından dile getirilmiştir.

Diğer yandan yarışmalar arasındaki ölçek farklılığı kent parçası ve kent bütünü arasındaki vazgeçilmez ilişkinin bazı durumlarda göz ardı edildiği ve dolayısıyla yarışmacılar tarafından da sorgulanmadan kabul edildiği fikrini getirmektedir. Bu durumlarda yarışmaların ruhunda yer alan esneklik, çok disiplinli katılıma yer açarken, çok ölçekli katılımı sınırlamaktadır. Şehir plancılarının ve mimarların çoğunlukla yer aldığı yarışma ekipleri üst ve alt ölçek çözümlerde esnekliği savunurken, çoğu zaman bir ölçekte kalıp, diğerini ikincil bırakabilmektedirler. Dolayısıyla büyük kentsel alanlardan daha noktasal kent parçalarına doğru kayan ölçek problemi de son dönemde yarışma kültürü içinde literatürün tartıştı̆̆ı önemli konulardan biri haline gelmiştir. Bu ölçek çeşitliliği kentsel tasarım yarışmalarının genellikle bireysel bir tasarımcı veya tasarımcı ekibinden ziyade çok disiplinli bir danışmanlık ekibinin becerilerini gerektirdiğinin de birincil kanıtıdır. Bu anlamda çoğu kentsel tasarım yarışmasına konu olan farklı ölçeklerdeki kent parçalarına müdahalede kentsel tasarım disiplinin temel alanları olan tarihi koruma, morfoloji, ulaşım, kentsel altyapı gibi konuları da ele alabilen bir perspektifte çok boyutlu bakış açılarına sahip profesyonellerden oluşan bir ekip yapısı kurgulanmalıdır (Lehrer, 2011, Sagalyn, 2006).

Son olarak, özellikle yarışmaların yerelde giderek etkin bir şekilde kullanılmaya başlaması, diğer bir deyişle yarışmaların yerelleşmesi, kentlinin kente ilişkin konulara dahil olduğu bir tasarıma doğru gelişmektedir. En bilinen örneklerinden biri olarak İngiltere'deki Trafalgar Meydanı'nın 2003'te sonuçlandırılan projelendirme sürecini verebileceğimiz bu yaklaşım, proje ve seçim aşamalarının kamuoyuyla paylaşıldığı, kentlinin de karar mekanizmalarına katkı koyduğu bir iletişim platformu önerilmiştir. Trafalgar örneğinde, 
yerel yönetim, sivil toplum örgütleri ve özel sektörün de katılımıyla, tarihsel anlamda çok önemli olan bir kentsel mekanın kentsel tasarım projesi çok aktörlü bir yöntemle oluşturulmuştur. Türkiye'de de son dönemde benzer katılımcı süreçler yürütülmeye çalışılmıştır. Bu anlamda 2 Mart 2020 tarihinde İstanbul Büyükş̧ehir Belediyesi'nin açtığı Taksim Kentsel Tasarım Yarışması şartnamesinde "jüri tarafindan seçilecek üç projenin açı olarak halka, paydaşlara sunumu ve bunun için meydanda hazırlanacak geçici bir bilgilendirme-iletişim merkezinde sergilenmesi" gibi bir yöntemle değerlendirileceği ibaresi yer almaktadır. Yine aynı şekilde Kadıköy Meydanı Kentsel Tasarım Yarışmasında jüri tarafından seçilen eşdeğer projelerden hangisinin uygulamaya geçeceğinde İstanbulluların da sözü olacağı belirtilmiş ve seçilen projeler Kadıköy Meydanında yarışmayı açan kurum tarafından kurulan "Karar Senin" merkezinde ya da istanbulsenin.org internet sitesinde İstanbul ilinde ikamet edenlerin oylamasına sunulmuştur. Her iki süreç de şu anda içinde yaşadığımız pandemi koşullarında uzaktan gerçekleştirilmiş ve sosyal medya ve uzaktan iletişim araçlarının önderliğinde ülkemizde tasarım konuşmalarına vesile da vesile olmuştur. Topluma katkının ve çok paydaşlı tasarım geleneğinin yaşatılması konusunda çok yararlı olduğunu düşündüğümüz bu süreçlerin tasarım kültürünü de ileri taşıyacağı aşikardır.

Lipstadt (2003) yarışmaların vazgeçilmez bir "süreç" olduğunu savunmakta, planlama ve mimarlık disiplinlerinin sanatsal ve profesyonel yönünü şekillendiren temel unsurlardan biri olarak görmektedir. Ancak yarışmaların mesleğe ve kentlere etkisini anlamak için mevcut araştırmalar sınırlıdır. Türkiye'nin dört bir yanındaki en çok kullanılan kamusal alanlara ve mahallelere şekil veren yarışma süreçleri hakkında daha fazla bilgiye ihtiyaç duyulmaktadır. Bu makale son yirmi yılın istatistiki verilerinden üretilen bir toplu resim oluşturmuş, ancak aynı zamanda daha fazla araştırma için de bir basamak olarak sunulmuştur. Gelecekteki kentsel tasarım yarışmaları çalışmaları hem kamu hem de özel kurumlar tarafından kullanılan karar verme modellerini sorgulamayı ve meslekten olmayan kişiler ile uzmanlar arasında kurulabilecek ilişkiler hakkında daha derin teorik perspektifler oluşturmayı amaçlamalidır. 


\section{Extended Abstract}

\section{Urban Design Competitions in Turkey: Definitions, Scales and Actors}

\author{
Pelin Yoncacı Arslan \\ ORCID: 0000-0003-3908-0653
}

\author{
Zeynep Eraydin \\ ORCID: 0000-0002-5505-7990
}

As of the first half of 2020, a series of urban design competitions are announced by the Istanbul Metropolitan Municipality and this trend is followed by big cities such as Bursa and Ankara Metropolitan Municipalities. Since antiquity, design competitions have been used by public and private organizations to select the designers of important public buildings and public spaces (Lipstadt 2003). Competitions, which have started to play an important role in architectural education, have become debatable in the academic environment with their contribution to theory and practice (Tostrup, 1999; Waern, 1996;. Yet, the literature on urban design policies and practices does not tend to highlight the role of design competitions in shaping both the built environment and the planning discipline.

The initial study on the history of the design competitions in Turkey, yet inadequately documented, demonstrates that neither a systematical impact analysis nor a professional archive is available for researchers. However, when concentrated on the available competition calls, specifications and project proposals, we come across clues about polyphonic and participatory design methods, competitive designers and competition processes and the ultimate contribution to urban culture. For this purpose, this study has created a database of 111 competitions from 1980 to 2020, using publicly available supplementary documents. The data was first categorized and then subjected to numerical and geographical data analysis with statistical methods. The aim is to revisit the Turkish competition environment; reveal the developments and changes in the 40-year period; underline interdisciplinary differences in the conception and 
the scale the competition sites; and finally suggests ways of which the contemporary design environment is affected by the 'competitive' disciplines of planning and architecture.

As studied and analyzed by many scholars, in Turkey, the competitions have played an important role in the spatial development of many cities since the first years of the Republic. The planning competitions processes started with international urban planning competitions, locally and regionally developed with Iller Bank in the 1940s and the Ministry of Public Works (Bayındırlık Bakanlığı) and the Ministry of Housing (İmar İskan Bakanlığı) in the 1960s and 1970s. Municipalities and ministries had an even more active role in the institutionalization of the competitions. (İdil, 2010; Şahin, 2010). In the period after 1980, the number of urban-scale competitions gradually increased while the definitions, in most case the 'definitive titles' of the competitions indicates a paradigm shift. After 1980s, the planning competitions were mostly replaced with architecture and urban design competitions. The language of competitions, which consists of names specific to the competition area such as "Local Development Plan (Mevzii İmar planı)", "Touristic Settlement Plan", "Urban Whole Reconstruction Plan (Kent Bütünü İmar Planı)," started to use the term urban design, first mentioned in 1981 with the "Eskişehir Fair and the Recreational, Entertainment, and Cultural Areas Urban Design competition." TMMOB (Chamber of Turkish Engineers and Architects) accepted the Project Competitions Regulation on Architecture, Engineering, Urbanism and Urban Design (Mimarlık Mühendislik Şehircilik ve Kentsel Tasarım Proje Yarışmaları Yönetmeliği). The regulation includes detailed decisions on the types of competitions, application principles, rules about the jury members and their duties, competition stages, rights and responsibilities of the competitive parties. Although the detailed examination of the document suggests that it contains important deficiencies regarding the concept, scope and process of urban design, many urban-scale design competitions have been organized in the binding of this document (Bayraktar, Kaplan ve Tekel, 2006).Thus, it has an important place in defining and shaping the competitions landscape.

Following Eskişehir competition announced under the title of urban design, 14 competitions were held in urban scale in the period of 1980-1989, but 6 of them were considered within the scope of landscaping, while only 8 were described as urban design competitions. While 8 of the 20 competitions held on an urban scale between 1990 and 1999 were urban design competitions, 14 of them were organized under the name of landscaping and landscape architecture competitions. With the 2000s, the number of urban design competitions 
started to increase gradually and 37 urban-scale competitions were organized in total between 2000-2009. Among these, only 9 were handled within the scope of landscaping, and 28 competitions were opened as urban design or urban and architectural design project competitions. In the period from 2010 until today, the method of obtaining projects by way of competition has been adopted more by the local administrations. A total of 40 urban-scale competitions were held and the term of urban design was mentioned in 24 of them (Table 1). When analyzed the region-wide distribution of these competitions, it is seen that only 35 of the 81 provinces have held an urban scale competition so far (Table 2). When we look at this graph as a map, on the other hand, the projects produced by the competitions are remarkably concentrated in the western provinces. (Figure 2). When we analyse the sama data in terms of the project sites and required scales, it is seen that competitions concentrating on a certain part of the city and/or a recreational area are most common ones, with a rate of approximately $35 \%$. These two main approaches are followed by competitons concerning city squares (25\%), surroundings of landmark buildings (10\%), coastal arrangements (4\%) and street arrangements (3\%) (Table 3).

Out of 111 competitions, only in 42 competitions (38\%) the participation of city planners as group members was obligatory. In $62 \%$ of the competitions, such a participation was not determined as a prerequisite. When these rules in the urban-scale competitions are compared along with the topics of these competitions, in 19 (54\%) of the competitions on the city part, city planners were required to be in the competition team, while in 16 (46\%) of them this obligation was not set as a criteria (Tables $5 a$ and $b$ ). These results are especially noteworthy if one considers the importance of establishing a relationship with the city and the area subject to the competition. The importance of the disciplinary knowledge and tools of the city planning and planners should be further emphasized for a sustainable and fair competitions landscape.

In conclusion, competitions are a design method that has been increasingly adopted in terms of both giving the participants the opportunity to express their ideas freely and providing the administration/clients with the opportunity to obtain many ideas. According to the American Institute of Architects (2010), competitions also have an important place in planning and design culture in terms of enabling citizens to be aware of the project-obtaining stages and to participate in the process. Lipstadt (2003) argues that competitions are an indispensable "process" and presents them as one of the basic elements that shape the artistic and professional aspects of planning and architecture disciplines. In 
Turkey, available research materials are limited to understand the effects of competitions on the profession and cities. This article has created a collective big picture produced from the statistical data of the last two decades, but it also functions as a stepping stone for further research. Future studies of urban design competitions should aim to question the decision-making models used by both public and private institutions and to create deeper theoretical perspectives on the relationships between citizens and experts.

\section{Kaynakça/References}

Alexander, E. R., L. P.Witzling, ve D. J.Casper (1987) Planning and urban design competitions: Organization, implementation and impacts. The Journal of Architectural and Planning Research, 4 (1), 31-46.

Alexander, E. R., Witzling. (1990) Planning and urban design competitions: Introduction and overview. Journal of Architectural and Planning Research, 7 (2), 91-104.

Altaban, O. (1998), Cumhuriyet' in kent planlama politikaları ve Ankara deneyimi. Sey, Y. (der.), 75 Yılda Değişen Kent ve Mimarlkk, Türkiye İş Bankası Kültürr Yayınları ve Tarih Vakfi, İstanbul.

Ayataç, H., ve Ketboğa, S. (2016). Alternatif bir üretim biçimi olarak kentsel tasarım proje yarışma süreçlerinin değerlendirilmesi. 10-22. Yarışmalar ve Mimarlk Sempozyumu Bildiri Kitapçı̆̆ı. 13.03.2021 tarihinde https:/issuu.com/arkitera/docs/issuu_455780227d3eeb adresinden erişilmiştir.

Banerjee, T. and Loukaitou-Sideris, A. (1990). Competitions as a design method: An inquiry. Journal of Architectural and Planning Research, 7 (2), 114-131.

Barnett, J. (2009). The way we were, the way we are: The theory and practice of designing cities since 1956. A. Krieger ve S. Saunders (Der.), Urban Design içinde, (s.101112). University of Minnesota Press.

Bayraktar, N., Kaplan, H. ve Tekel, A. (2006). Kentsel tasarım - Yarışma süreçleri ve uygulama örnekleri üzerinden kentsel tasarım tartı̧maları. Mimarlkk, 329, 14-33.

Bilsel, C. (2010). Turkiye'de şehircilik yarışmalarının ilk otuz yllı (1927-1957): Cumhuriyet' in kent inşasında uluslararası deneyim. Planlama, 50, 29-46.

Chupin, J. ve Cucuzzella, C. (2011). Environmental standards and evaluation processes in competitions for public buildings. Geographica Helvetica 66:1, 1-11.

Collyer, G. S. (2004). Competing globally in architecture competitions. Academy Press.

Çimen, D. (2010). Urban design competitions As discursive practice in Turkey: 1980-2009. (Yayımlanmamış doktora tezi). ODTÜ, Ankara.

Çimen, D. (2013). Söylemsel düzlem olarak Türkiye'de yarışmalar: Kentsel tasarım yarışmaların isimlendirmek. Yarı̧malar ve Mimarlık Sempozyumu Bildiri Kitabı. 88-95. 13.03.2021 tarihinde https://issuu.com/arkitera/docs/sempozyum_2013_tr_web adresinden erişilmiştir.

De Haan H. (1988). Architecten als rivalen: Tweehonderd jaar architectuurprijsoragen. Meulenhoff/Landshoff 
Gosling D. ve Maitland B (1984) Concepts of urban design. London: St. Martin Press.

Gülgeç, İ. (2010). İller Bankası'nın imar planlama yarışmalarına ait notlar. Planlama. 50, 47-50.

İdil, B. (2010). Planlama ve kentsel tasarım yarışmaları. Planlama, 50, 55-60.

Jessop, B., (2002), Liberalism, neoliberalism, and urban governance: A state-theoretical perspective. Antipode, 34(3), 452-472.

Larson, M. S. (1994). Architectural competitions as discursive events. Theory and Society 23 (4), 469-504.

Lehrer, U., (2011). Urban design competitions. Tridib Banerjee ve Anastasia LoukaitouSideris (der.). Companion to Urban Design içinde (s.304-316). New York: Routledge.

Lipstadt, H. (2003). Can 'Art Professions' be Bourdieuean fields of cultural production? The case of the architecture competition. Cultural Studies, 17 (3-4), 390-419.

Lipstadt, H. (2006) The competition in the region's past, the region in the competition's future. C.Malmberg (der.), The Politics of Design: Competitions for Public Projects, içinde, (s.7-28). Princeton, NJ: The Policy Research Institute for the Region, Princeton University.

Malmberg, C. (2006). (Der.) The politics of design: Competitions for public projects. Princeton NJ: The Policy Research Institute for the Region, Princeton University.

Özaydın, G. (2008). İstanbul'da kentsel tasarım yarışmalarına bir bakış. Mimarist, 8(29) 68-75.

Özdağlar G. O. ve Ömür Yılmaz, Z. (der.) (2004). Yarışmalar dizini (1930-2004), TMMOB Mimarlar Odası Genel Merkezi ve Ankara Şubesi, Ankara.

Rönn, M., Kazemian, R., ve J. E. Andersson (der.) (2010) The architectural competition. research, Inquiries and experiences. Axl Books.

Sagalyn, L., (2006), Political fabric of design competitions. C.Malmberg (Der.), The politics of design: Competitions for public projects, içinde (s.29-52). Princeton NJ: The Policy Research Institute for the Region, Princeton University.

Sayar, Y. (2004). Türkiye'de mimari proje yarışmaları 1930-2000: Bir değerlendirme. Mimarlik sayı:320.

Sert, J. L. (1956). Urban design. Progressive Architecture. 97-112.

Sirel, A. ve Sirel O. Ü. (2016) Kentsel tasarım proje yarışmalarının uygulanma sorunları. 50-50-9. Yarışmalar ve Mimarlık Sempozyumu Bildiri Kitapçı̆̆̆. İstanbul 13.03.2021 tarihinde https://issuu.com/arkitera/docs/issuu_455780227d3eeb) adresinden erişilmiştir.

Sudjic, D (2006). Design competitions: the pitfalls and the potential. C.Malmberg (Der.), The Politics of Design: Competitions for Public Projects, içinde (s.53-66). Princeton NJ: The Policy Research Institute for the Region, Princeton University.

Spreiregen, P. D.(1979). Design competitions. New York: McGraw-Hill.

Svensson, C. (2008). Arkitekttävlingar, om konsten att hitta en vinnare, diss. KTH. Stockholm: Kungl Tekniska Högskolan. 
Şahin, S. Z. (2010). İktidar, meşruiyet, planlama ve kentsel tasarım yarışmaları ilişkisi: Aracsallıktan platformluğa uzanan bir yol. Planlama, 50, 9-28.

Tostrup, E. (1999). Architecture and rhetoric: Text and design in architectural competitions. Papadakis Publisher.

Arkitera Mimarlık Merkezi, (2016). Yarışmalar ve Mimarlk Sempozyumu. İstanbul

TMMOB Mimarlar Odası. (2001). Mimarlk Mühendislik Şehircilik ve Kentsel Tasarım Proje Yarışmaları Yönetmeliği. Ankara. 